\title{
Biogenic silver nanoparticles associated with silver chloride nanoparticles (Ag@AgCl) produced by laccase from Trametes versicolor
}

Nelson Durán ${ }^{1,2^{*}}$, Raphael Cuevas ${ }^{3,4}$, Livia Cordi ${ }^{5}$, Olga Rubilar ${ }^{4,6}$ and Maria Cristina Diez ${ }^{4,6}$

\begin{abstract}
In the present study, semi-purified laccase from Trametes versicolor was applied for the synthesis of silver nanoparticles, and the properties of the produced nanoparticles were characterized. All of the analyses of the spectra indicated silver nanoparticle formation. A complete characterization of the silver nanoparticles showed that a complex of silver nanoparticles and silver ions was produced, with the majority of the particles having a $\mathrm{Ag}^{2+}$ chemical structure. A hypothetical mechanistic scheme was proposed, suggesting that the main pathway that was used was the interaction of silver ions with the T1 site of laccase, producing silver nanoparticles with the concomitant inactivation of laccase activity and posterior complexing with silver ions.
\end{abstract}

Keywords: Silver nanoparticles; Silver chloride nanoparticle; Laccase; T. versicolor

\section{Introduction}

The literature has demonstrated that the mechanism used for the formation of metal nanoparticles is the action of a large number of enzymes secreted by fungi in special reductases (Ahmad et al. 2003; Durán et al. 2007; Durán et al. 2011; Jain et al. 2011). Currently, the use of white-rot fungi for the production of metal nanoparticles is a recent branch of research with less than a decade of study (Rubilar et al. 2008; Tortella et al. 2008; Acevedo et al. 2012). The number of reports on synthesis is very limited, and the use of different species of fungi has been limited to a few species, such as $P$. chrysosporium (Vigneshwaran et al. 2009), Pleurotus sajor caju (Nithya and Ragunathan 2009), Coriolus versicolor (Sanghi and Verma 2009), Pycnoporus sanguineus (Chan and Don 2012a) and Shizophyllum commune (Chan and Don 2012b). Furthermore, Sanghi et al. (Sanghi et al. 2001) demonstrated that the laccase enzyme secreted by Phanerochaete chrysosporium white-rot fungus was responsible for the formation of gold nanoparticles. At the same time, it was reported that a laccase from the ascomycete

\footnotetext{
* Correspondence: duran@iqm.unicamp.br

'Biological Chemistry Laboratory, Instituto Química, Universidade Estadual de Campinas, CP 6154, CEP 13083-970 Campinas, SP, Brazil

${ }^{2}$ Laboratory on Nanostructures Synthesis and Biosystems Interactions

(NanoBioss) (UNICAMP/SP), Campinas, SP, Brazil

Full list of author information is available at the end of the article
}

Paraconiothyrium variabile was isolated from soil, and a blue enzyme with laccase activity was purified and characterized (Forootanfar et al. 2011). This enzyme was also able to produce gold nanoparticles (Faramarzi and Forootanfar 2011).

In this context, white-rot fungi isolated from temperate forests in southern Chile have potential for biosynthesizing metal nanoparticles due to their high production of extracellular enzymes, such as laccase and peroxidases (Tortella et al. 2008), which have been shown to biosynthesize metal nanoparticles (Vigneshwaran et al. 2009).

The aim of this study was to evaluate the biosynthesis of silver nanoparticles through the semi-purification of laccase from Trametes versicolor, a white-rot fungus, as well as to characterize the nanoparticles by electronic microscopy, analysis of the distribution of size by DLS measurements, stability of the nanoparticles by Zeta potential and, finally, by FTIR and XRD.

\section{Materials and methods Laccase production}

Laccase was obtained from T. versicolor and semi-purified following a previous published procedure (Cordi et al. 2007; Leonowicz and Grzywnowicz 1981), and the silver nanoparticles were obtained after incubation in the presence of silver nitrate. Briefly: Laccase was obtained from 
T. versicolor (CCT 4521) cultivated for $4-20$ days at $30^{\circ} \mathrm{C}$ while shaking at $240 \mathrm{rpm}$ in liquid medium following Cordi et al. (2007) Laccase production was induced by copper sulfate $\left(0.1 \mathrm{mmol} \mathrm{L}^{-1}\right)$ and 2,5-xylidine $\left(1 \mathrm{mmol} \mathrm{L}^{-1}\right)$ with $96 \mathrm{~h}$ of fungal culture.

\section{Laccase semi-purification}

The purification followed the previously published results of Cordi et al. (Cordi et al. 2007). The culture filtrate from the procedure described above in the presence of $0.1 \mathrm{mmol} \mathrm{L}^{-1}$ of copper sulfate (through 380 mesh) was frozen, thawed, filtrated through a Millipore $0.45 \mathrm{~mm}$ membrane and lyophilized. A solution containing $2.0 \mathrm{~g}$ of lyophilized crude extract, $30 \mathrm{~mL}$ of citrate-phosphate and buffer (75 $\mathrm{mmol} \mathrm{L}^{-1}, \mathrm{pH}$ 5.0) was precipitated with $90 \%$ ammonium sulfate. The precipitate was eluted in a Sephacryl S-200 (Sigma) column using the same buffer as the mobile phase. The fractions containing laccase activity were collected. Another precipitation and elution was performed to eliminate the dark pigments from the filtrate. The fractions with laccase activity were collected and lyophilized. The lyophilized sample was resuspended in $10 \mathrm{mmol} \mathrm{L}^{-1}$ (pH 5.0) citrate-phosphate buffer and applied to a column containing DEAE cellulose (Leonowicz and Grzywnowicz 1981). The laccase was eluted with $10 \mathrm{mmol} \mathrm{L}^{-1}$ citrate-phosphate buffer, and a $\mathrm{NaCl}$ gradient of zero to $1 \mathrm{~mol} \mathrm{~L}^{-1}$ was applied. The fractions obtained were lyophilized and stored in a freezer (Cordi et al. 2007).

\section{Enzyme activity assay}

The reagent syringaldazine was used as a substrate for the spectrophotometric determination of the laccase activity. Briefly: a reaction mixture containing $0.6 \mathrm{~mL}$ of enzymatic solution, $0.3 \mathrm{~mL}$ of citrate-phosphate buffer $0.05 \mathrm{M}(\mathrm{pH} 5.0)$ and $0.1 \mathrm{ml}$ of syringaldazine $(1 \mathrm{mM})$ at a final volume of $1 \mathrm{~mL}$ was mixed for $5 \mathrm{~min}$, and the absorption at $525 \mathrm{~nm}\left(\varepsilon_{525}=65000 \mathrm{M}^{-1} \mathrm{~cm}^{-1}\right)$ was measured. One laccase unit was defined as the enzyme quantity needed to oxidize $1 \mathrm{mmol}$ of syringaldazine $\mathrm{min}^{-1}$ per liter of total enzymatic solution (Cordi et al. 2007).

\section{Preparation of silver nanoparticles}

An aqueous solution of $200 \mathrm{UL}^{-1}$ semi-purified laccase (stock solution of $2300 \mathrm{U} \mathrm{L}^{-1}$ ) was added to an aqueous solution of $1 \mathrm{mmol} \mathrm{L}^{-1}$ silver nitrate followed by the incubation of the reaction mixture in the dark at different temperatures $\left(30-50^{\circ} \mathrm{C}\right)$. The formation of a brown color indicated the production of silver nanoparticles (Durán et al. 2007).

\section{Characterization of silver nanoparticles UV-Visible Spectroscopy}

UV-Visible spectrophotometer (UV-1650 PC Shimadzu) and Spectronic Genesys GS at a range of wavelength of 200-800 nm was used.

\section{$X$-Ray Diffraction (XRD) Studies}

XRD spectra was recorded on a Shimadzu XRD 7000 instrument, and depicted number of Bragg reflections indexed on the basis of the face centered cubic (FCC) structure of metallic silver.

\section{Particle size (DLS) analysis and Potential Zeta}

The hydrodynamic diameter and zeta potential values of the produced silver nanoparticles were assessed with a Malvern Zetasizer Nanosystem (Worcestershire, UK). The aqueous suspension of the synthesized silver nanoparticles was filtered through a $0.22 \mu \mathrm{m}$ syringe driven filter unit and the size of the distributed silver nanoparticles were measured by using the principle of dynamic light scattering (DLS) technique made in a Malvern Zetasizer Nano series compact scattering spectrometer.

\section{Transmision Electron Microsocopy (TEM)}

TEM images of the samples were obtained using a transmission electron microscope (model JEOL JEM 1200EX II), at a Filament; Tungsten Voltage, kV; 40-120 kv. The elemental analysis was carried out in spectrum of energy dispersive X-ray technique.

\section{Fourier Transform Infrared Spectroscopy (FTIR)}

Characterization of silver nanoparticles was carried out by FTIR using CARY 630 FTIR Agilent Technologies in the range $600-4000 \mathrm{~cm}^{-1}$. FTIR reveals the biomolecules responsible for the reduction of silver ions and stabilization of AgNPs in the solution.

\section{Scanning Electron Microscopy (SEM)}

SEM micrograph was taken using a JEOL 6360LV instrument, $40 \mathrm{kV}$. The samples were fixed with $2.5 \%$ glutaraldehyde overnight at room temperature followed by dehydration with gradient alcohol (10\% to $95 \%)$ for $20 \mathrm{~min}$ and then in absolute alcohol for 2-5 min. The final specimen was prepared by coating the dehydrated sample with monolayer platinum for making the surface conducting.

\section{Results and discussions}

\section{Laccase production}

From the kinetics of laccase production, it was shown that the best laccase activity was reached after 12 days under the studied conditions.

It was previously demonstrated that laccase activity was negligible in the absence of copper sulfate in in this 
culture (Cordi et al. 2007). The highest laccase activity was observed at $0.100 \mathrm{mmol} \mathrm{L}{ }^{-1}$ copper sulfate, and the value was $41,000 \mathrm{U} \mathrm{L}^{-1}$ at the 12th day (Figure 1). The laccase semi-purification shows that most of the pigments present in the crude extract were removed by the Sephacryl S-200 step (Table 1). The lower laccase activity compared to the crude extract was most likely due to the purification of isoenzymes. The final fraction from Sephacryl S-200 (Leonowicz and Grzywnowicz 1981) was used in all of the experiments in this study.

\section{Reduction of a silver ion solution by laccase}

The absorption spectra of an untreated and treated silver solution (Figure 2) indicated the formation of silver nanoparticles due to the presence of the surface plasmon absorption of silver nanoparticles between 420 to $440 \mathrm{~nm}$. The absorption of laccase (T1 site) at $600 \mathrm{~nm}$, after the addition of silver ions, disappeared completely with the concomitant loss of laccase activity (Figure 2, insertion).

The wide plasmonic band of this interaction of silver ions and laccase is most likely an indication that another nanometric species is present. This is discussed later because the XRD shows the formation of silver chloride nanoparticles, in addition to silver nanoparticles, similarly with a plasmonic band at $440-460 \mathrm{~nm}$, as previously described by Gopinath et al. (2013).

The effect of temperature on the size of the silver nanoparticles was also studied and showed a 90 to $370 \mathrm{~nm}$ distribution from $30^{\circ} \mathrm{C}$ to $70^{\circ} \mathrm{C}$ of silver nanoparticles after $72 \mathrm{~h}$ of incubation (data no shown). The nanoparticles produced at $50^{\circ} \mathrm{C}$ showed particle size distributions of approximately $200 \mathrm{~nm}$ at $\mathrm{pH} 9$ (Figure 3 ).

Figure $3 \mathrm{~A}$ shows the $\mathrm{pH}$ effect on the size distribution of the silver nanoparticles at $50^{\circ} \mathrm{C}(72 \mathrm{~h})$. A similar size of approximately $100 \mathrm{~nm}$ at $\mathrm{pH} 5$ and $\mathrm{pH} 7$ was observed.
However, at $\mathrm{pH} 9$, an agglomeration occurred, resulting in an increase in the size distribution of up to $200 \mathrm{~nm}$. Figure 3B shows the zeta potential of the silver nanoparticles formed at $\mathrm{pH} 9$ and $50^{\circ} \mathrm{C}(72 \mathrm{~h})$ of $-30.0 \mathrm{mV}$, showing a negative charge distribution of the silver nanoparticle surface.

\section{Characterization of silver nanoparticles}

Figure $3 \mathrm{C}$ shows an X-ray diffraction (XRD) pattern that is compatible with the cubic phase of Ag with diffractions points at $38^{\circ}, 45^{\circ}, 64.5^{\circ}, 78^{\circ}$ and $81.7^{\circ}$ of $2 \theta$, which can be indexed to the (111), (200), (220), (311) and (222) planes of the facet centered cubic (FCC) structure (JCPDS file: 65-2871) that coexists with the cubic phase of $\mathrm{AgCl}$ at $27.9^{\circ}, 32.3^{\circ}, 46.3^{\circ}, 55.0^{\circ}, 57.6^{\circ}, 67.6^{\circ}, 74.6^{\circ}$, $76.9^{\circ}$, and $85.7^{\circ}$ and that corresponds to the (111), (200), (220), (311), (222), (400), (331), (420), and (422) planes (JCPDS file: 31-1238).

This XRD pattern clearly shows a pattern from the interaction of silver nanoparticles with silver ions $\left(\mathrm{Ag}_{2}^{+}\right.$ complex), represented normally as the Ag@AgCl product (Wang et al. 2008). The chlorine ions likely come from the semi-purification of the laccase process.

FTIR measurements (not shown) of silver nanoparticles and their bands were observed at $3440-2325 \mathrm{~cm}^{-1}$, corresponding to the $\mathrm{NH}$ stretching vibration of primary and secondary amines in the protein molecule. Bands at $1634 \mathrm{~cm}^{-1}, 1541 \mathrm{~cm}^{-1}$ and $1384 \mathrm{~cm}^{-1}$ are attributed to the $\mathrm{C}=\mathrm{C}$ and $\mathrm{C}-\mathrm{H}$ of the methyl group, which are present in protein. The absorption peaks at $1236 \mathrm{~cm}^{-1}$ and $1048 \mathrm{~cm}^{-1}$ are assigned to the $-\mathrm{C}-\mathrm{O}$ and $-\mathrm{C}=\mathrm{O}$ of aromatic acids and esters, respectively. The peak at $1452 \mathrm{~cm}^{-1}$ is attributed to the symmetric stretching vibrations of the - $\mathrm{COO}$ - groups of amino acid residues. The peak at $1653 \mathrm{~cm}^{-1}$ corresponds to the presence of amide I and amide II, which arises due to the carbonyl

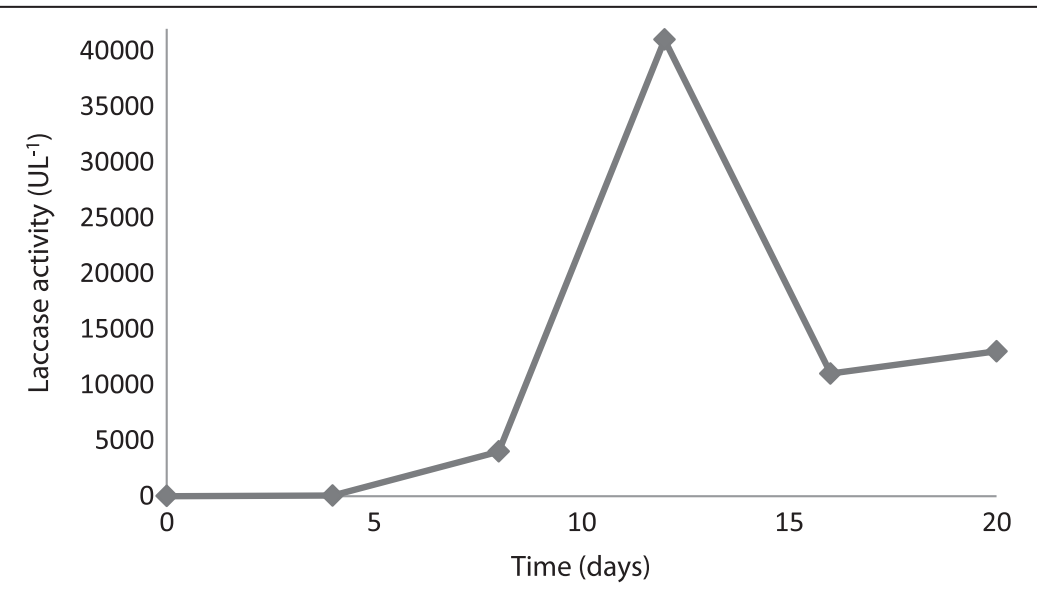

Figure 1 Laccase activity versus time (days) in the presence of $T$. versicolor at $0.1 \mathrm{mmol} \mathrm{L}^{-1}$ of copper sulfate and $1 \mathrm{mmol} \mathrm{L}^{-1}$ of 2,5 -xylidine at $30^{\circ} \mathrm{C}$ (average values of three independent measurements $\pm 2 \%$ error). 
Table 1 Extracellular laccase semi-purification from T. versicolor

\begin{tabular}{lccccc}
\hline Purification (Steps) & Volume $(\mathbf{m L})$ & Total activity $\left(\mathbf{U ~ L}^{-\mathbf{1}}\right)$ & Total protein Content $\left(\boldsymbol{\mu g ~ \mathbf { ~ L } ^ { - 1 } )}\right.$ & Specific activity $\left(\mathbf{U ~ m g}^{-\mathbf{1}}\right)$ & Purification (folds) \\
\hline $\begin{array}{l}\text { Crude extract } \\
\text { Precipitation }\left(\mathrm{NH}_{4}\right)_{2} \mathrm{SO}_{4}\end{array}$ & 900 & 2700 & 2500 & 1 & 1 \\
$\begin{array}{l}\text { Sephacryl S-200 (1) } \\
\text { Precipitation }\left(\mathrm{NH}_{4}\right)_{2} \mathrm{SO}_{4}\end{array}$ & 60 & 8600 & 415 & 21 & 10 \\
Sephacryl S-200 (2) & 44 & 10300 & 277 & 37 & 35
\end{tabular}

stretch and -N-H- stretch vibration. These data indicate the presence of protein capping in $\mathrm{Ag@AgCl}$ nanoparticles.

A transmission electron microscopy (TEM) image of silver nanoparticles is shown in Figure 3D. The micrographic image confirmed that the synthesized $\mathrm{Ag@AgCl}$ nanoparticles were spherical in shape, and the size of the particles was less than $100 \mathrm{~nm}$, which correlates with the DLS measurements.

Then, laccase from $T$. versicolor, a white-rot fungi, showed reductive action for the synthesis of silver nanoparticles. Incubating the semi-purified laccase in the presence of silver ions at different temperatures reduced $\mathrm{Ag}^{+}$to $\mathrm{Ag}^{\mathrm{O}}$ and interaction with silver ions generated Ag@AgCl nanoparticles. The chloride ions most likely come from the semi-purification of laccase, as previously described. Increasing the incubation temperature from $30^{\circ} \mathrm{C}$ to $50^{\circ} \mathrm{C}$ decreased the time for the formation of nanoparticles, and at $50^{\circ} \mathrm{C}$, the production of large nanoparticles was achieved within a few minutes. It was also observed that the particle size and the distribution of the obtained nanoparticles were inversely dependent on the temperature over a range of 30 to $50^{\circ} \mathrm{C}$. Additionally, there was a $\mathrm{pH}$ dependence of the size distribution, and at a lower $\mathrm{pH}$, smaller sized nanoparticles were found.
This finding is interesting because the biogenic synthesis of silver chloride nanoparticles by Bacillus subtillis (Paulkumar et al. 2013) and from leaf extracts of Cissus quadrangularis Linn was recently published (Gopinath et al. 2013).

\section{Mechanistic aspects on biogenic synthesis of $\mathrm{Ag} @ \mathrm{AgCl}$}

Because there are no quinones or any other intermediates in this reduction, it must be considered to be a different type of reduction process. There are many possibilities for this reduction, as previously described for other enzymes in the literature. The production of silver nanoparticles by laccase is mostly likely due to the presence of free cysteine as a reducing group. The laccase from $T$. versicolor exhibits one cysteine associated with $\mathrm{Cu} 1-\mathrm{S} \gamma$ (Cys-453) laccase and is stabilized by a disulfide bridge to domain 1 (Cys-85-Cys-488), and a second disulfide bridge (Cys-117-Cys-205) connects domains 1 and 2 of laccase (Piontek et al. 2002).

All of the data indicated that cysteine was acting as reductant, as previously described from the amylase generation of gold nanoparticles through $\mathrm{Au}-\mathrm{S}$ bonds with the retention of the biological activity of the enzyme (Rangnekar et al. 1997). In a similar direction, the comparison of laccase stability profiles at different temperatures during the gold nanoparticle synthesis showed that

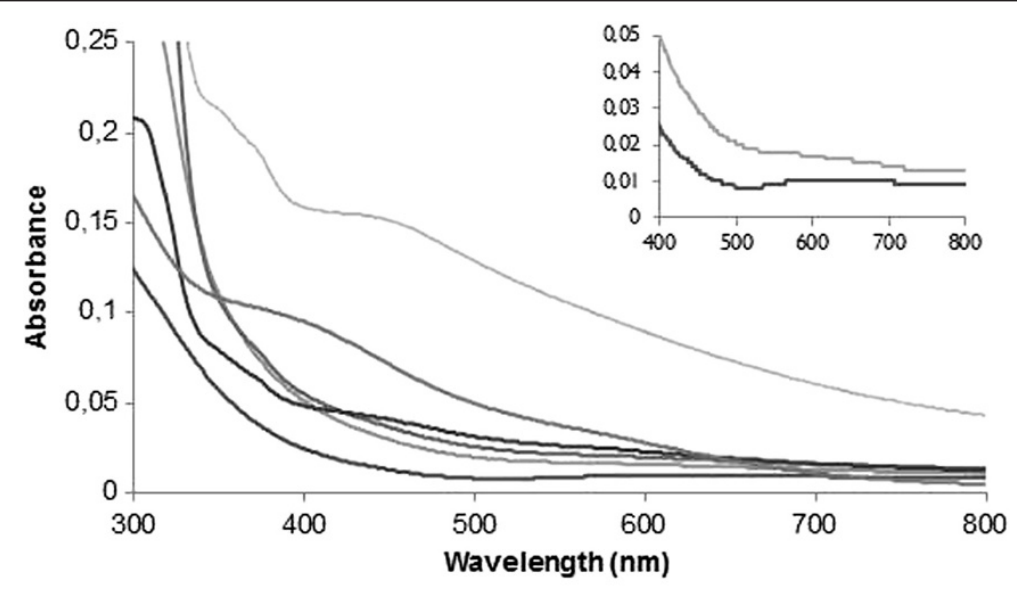

- Control Laccase $-0 \mathrm{~h}-3 \mathrm{~h}-24 \mathrm{~h}-48 \mathrm{~h}-72 \mathrm{~h}$

Figure 2 UV-Visible absorption spectra of silver nanoparticles using a $1 \mathrm{mM}$ AgNO3 solution in the presence of semi-purified laccase

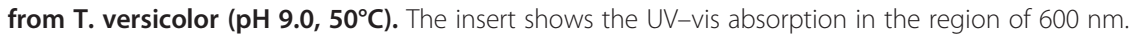



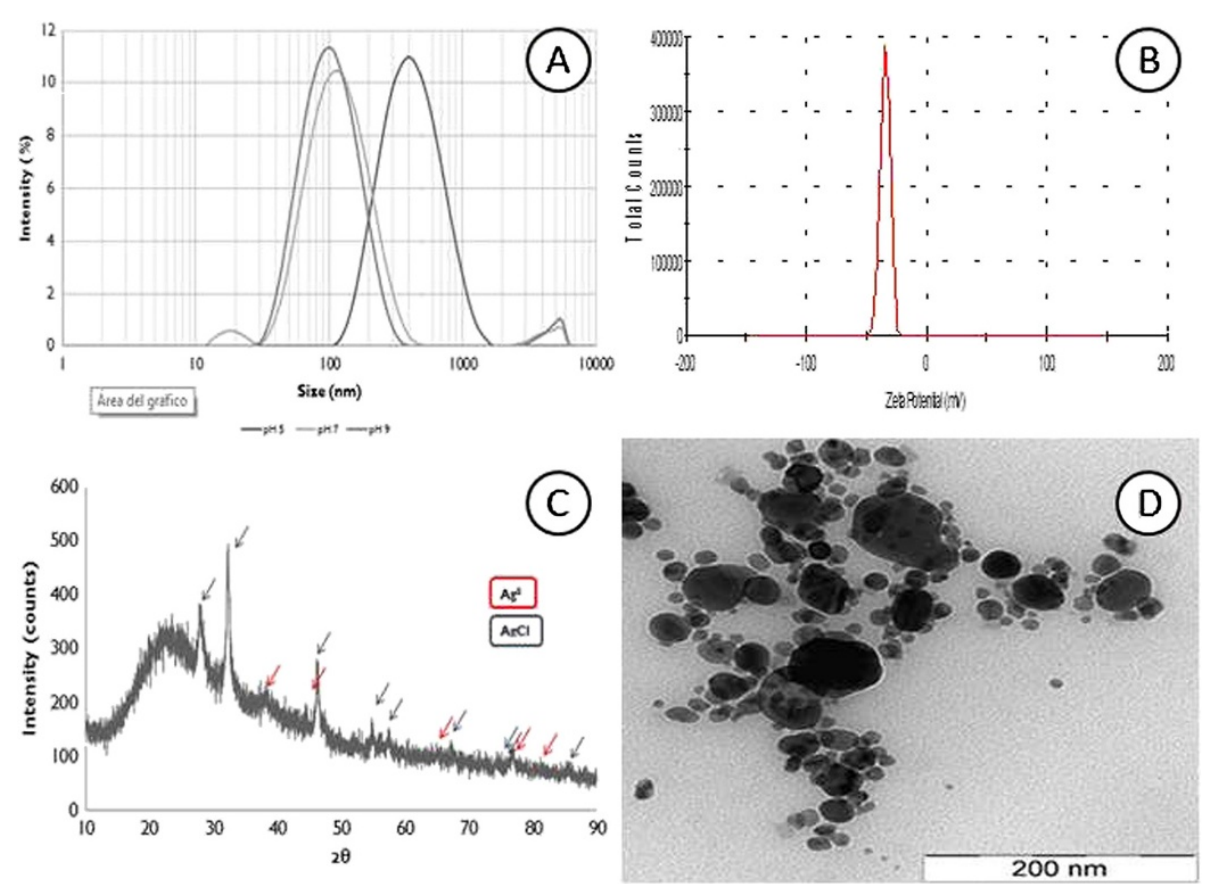

Figure 3 Characterization of silver nanoparticles. (A) Dynamic Light Scattering (DLS). (B) Zeta potential. (C) XRD pattern. (D) Transmission electron micrograph (TEM).

the formation of gold nanoparticles occurred when the activity decreased, meaning that thiols as reducing functional groups might be responsible for forming gold nanostructures (Faramarzi and Forootanfar 2011). This finding was in agreement with the study of Kalishwaralal et al. (2010), which demonstrated that denaturation of the purified amylase increased the rate of gold nanoparticle biosynthesis by exposing the reductive groups (thiol groups) of cysteine to a gold solution. Similar findings and explanations were reported for silver reduction by urease (Sharma et al. 2013).

Eby et al. (2009) synthesized antibacterial silver nanoparticles in an organic solution using lysozyme as the reducing and capping agent, but no aspect of the mechanism were discussed. In the case of lysozyme silver nanoparticles synthesis, hydroxyl groups in tyrosine residues and amine groups in tryptophan residues were found to be responsible for this production (Kumar et al. 2012).

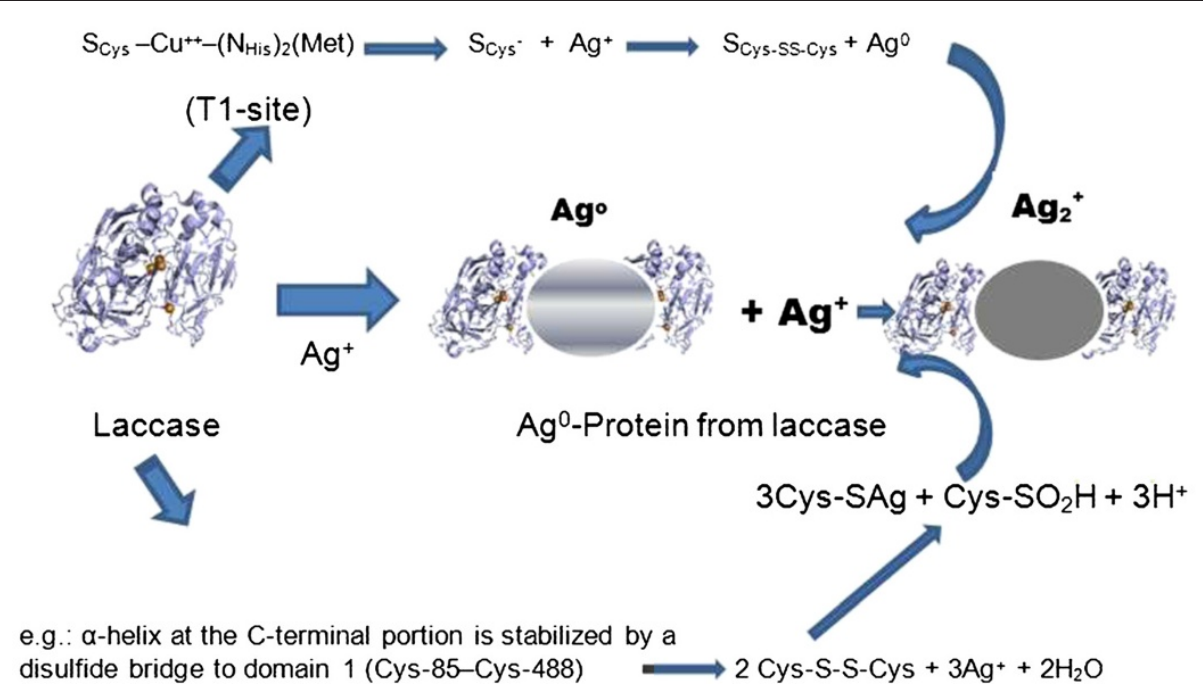

Scheme 1 Hypothetical mechanistic interaction between laccase and silver ions producing silver nanoparticles. 
As previously discussed, in the case of laccase from $T$. versicolor, on the bases of all of the data discussed, two different mechanisms are possible: one involves cysteine associated to $\mathrm{Cu}$ type I (T1 site) (sulfhydryl group of cysteine- $\mathrm{Cys}^{-}$) in the laccase structure reacting with the silver ion, reducing it to silver nanoparticles while the cysteine anion is oxidized to Cys-Cys in the laccase. The T1 site of laccase imparts a light blue color to the enzyme solutions and is characterized by a distinctly pronounced band of optic absorption at a wavelength of $600 \mathrm{~nm}$ (Morozova et al. 2007). This suggested mechanism is possible because, in this study, a rapid disappearance of the absorption band at approximately $600 \mathrm{~nm}$ in the $T$. versicolor laccase occurred after the addition of silver ions with complete inactivation of the enzyme (Figure 1 inserted). The second possibility is the direct interaction of silver ions with the Cys-Cys moiety, generating silver nanoparticles, and the sulfhydryl moiety bound to silver nanoparticles as capped proteins (Cecil and McPhee 1957) (Scheme 1).

This interaction of silver ions and the Cys-Cys moiety in the laccase domain most likely inactivates the enzyme, as observed in this study.

This new concept of non-enzymatic catalytic biogenic silver nanoparticles expands the possibilities of the actual syntheses of the biogenic silver nanoparticles (Gade et al. 2008; Bawaskar et al. 2010; Gaikwad et al. 2013; Edmundson et al. 2014; Kashyap et al. 2013; Birla et al. 2013; Tran et al. 2013; Ingale and Chaudhari 2013). The combination of silver chloride nanoparticles, as was detected in this case, associated to silver nanoparticles is another aspect of the great potential of these nanostructures, as shown by previous results of the microbial or photocatalytic activities of silver chloride nanoparticles (Paulkumar et al. 2013; Choi et al. 2008; Min et al. 2010; Naik et al. 2011; Wang et al. 2008).

\section{Final remarks}

The actual data on the biogenic synthesis of $\mathrm{Ag} @ \mathrm{AgCl}$ nanoparticles with laccase demonstrated that the sulfhydryl group is the reducing agent. The most important aspect of this reaction is the sulfur group at the T1 site of laccase activity. The typical absorption band of this blue protein of approximately $600 \mathrm{~nm}$ disappeared immediately after the addition of silver ions with the concomitant loss of laccase activity. The interaction with the sulfur-sulfur bridge directly generates the reduction, and binding to the laccase proteic moiety is another possibility. The Ag@AgCl nanoparticles appeared to be a potential antimicrobial in addition to possessing the activities of silver nanoparticles alone.

\section{Competing interests}

The authors declare that they have no competing interests.

\section{Authors' contributions}

The manuscript was written through contributions of all authors. All authors have given approval to the final version of the manuscript a contributed equally.

\section{Acknowledgments}

Support from FAPESP, CNPq, INOMAT (MCTI/CNPq), NanoBioss (MCTI), Brazilian Network on Nanotoxicology (MCTI/CNPq), FONDECYT project N ${ }^{\circ}$ 1130854 and CONICYT Scholarship 21110491(Chile), Environmental Biotechnology Center (UFRO-Chile) and IQ-UNICAMP (Brazil) is acknowledged.

\section{Author details}

${ }^{1}$ Biological Chemistry Laboratory, Instituto Química, Universidade Estadual de Campinas, CP 6154, CEP 13083-970 Campinas, SP, Brazil. Laboratory on Nanostructures Synthesis and Biosystems Interactions (NanoBioss) (UNICAMP/ SP), Campinas, SP, Brazil. '3 Doctoral Program of Science of Natural Resources, Universidad de La Frontera, Temuco, Chile. ${ }^{4}$ Environmental Biotechnology Center Science Nucleus BIOREN, Universidad de La Frontera, Temuco, Chile. ${ }^{5}$ Institute of Biology, Universidade Estadual de Campinas, Campinas, SP, Brazil. ' Department of Chemical Engineering, Universidad de La Frontera, Temuco, Chile.

Received: 26 August 2014 Accepted: 17 October 2014

Published: 31 October 2014

\section{References}

Acevedo F, Pizzul L, Castillo MP, González ME, Cea M, Gianfreda L, Diez MC (2012) Degradation of polycyclic aromatic hydrocarbons by free and nanoclay-immobilized manganese peroxidase from Anthracophyllum discolor. Chemosphere 80:271-278

Ahmad A, Mukherjee P, Senapati S, Mandal M, Khan MI, Kumar R, Sastry M (2003) Extracellular biosynthesis of silver nanoparticles using the fungus Fusarium oxysporum. Colloids Surf B: Biointerf 28:313-318

Bawaskar M, Gaikwad S, Ingle A, Rathod D, Gade A, Durán N, Marcato PD, Rai M (2010) A new report on mycosynthesis of silver nanoparticles by Fusarium culmorum. Curr Nanosci 6:376-380

Birla SS, Gaikwad SC, Gade AK, Rai MK (2013) Rapid synthesis of silver nanoparticles from fusarium oxysporum by optimizing physicocultural conditions. SciWorld J 2013:Article ID796018

Cecil R, McPhee JR (1957) Further studies on the reaction of disulphides with silver nitrate. Biochem J 66:538-543

Chan YS, Don MM (2012a) Characterization of Ag nanoparticles produced by white-rot fungi and its in vitro antimicrobial activities. Intern Arabic J Antimicrob Agents $2 \mathrm{~N}(3): 3$

Chan YS, Don MM (2012b) Biosynthesis and structural characterization of Ag nanoparticles from white rot fungi. Mat Sci Eng 33:282-288

Choi OK, Deng KK, Kim NJ, Ross L, Hu ZQ (2008) The inhibitory effects of silver nanoparticles, silver ions and silver chloride colloids on microbial growth. Water Res 42:3066-3074

Cordi L, Minussi RC, Freire RS, Durán N (2007) Fungal laccase: copper induction, semi-purification, immobilization, phenolic effluent treatment and electrochemical measurement. Afr J Biotechnol 6:1255-1259

Durán N, Marcato PD, Souza G, Alves OL, Esposito E (2007) Antibacterial effect of silver nanoparticles produced by fungal process on textile fabrics and their effluent treatment. J Biomed Nanotechnol 3:203-208

Durán N, Marcato PD, Durán M, Yadav A, Gade A, Rai M (2011) Mechanistic aspects in the biogenic synthesis of extracellular metal nanoparticles by peptides, bacteria, fungi and plants. Appl Microbiol Biotechnol 90:1609-1624

Eby DM, Schaeublin NM, Farrington KE, Hussain SM, Johnson GR (2009) Lysozyme catalyzes the formation of antimicrobial silver nanoparticles. ACS Nano 3:984-994

Edmundson MC, Capeness M, Horsfall L (2014) Exploring the potential of metallic nanoparticles within synthetic biology. New Biotechnol http://dx.doi.org/ 10.1016/j.nbt.2014.03.004

Faramarzi MA, Forootanfar H (2011) Biosynthesis and characterization of gold nanoparticles produced by laccase from Paraconiothyrium variabile. Colloids Surf B: Biointerf 87:23-27

Forootanfar H, Faramarzi MA, Shahverdi AR, Yazdi MT (2011) Purification and biochemical characterization of extracellular laccase from the ascomycete Paraconiothyrium variabile. Bioresour Technol 102:1808-1814 
Gade A, Bonde P, Ingle AP, Marcato PD, Durán N, Rai MKJ (2008) Exploitation of Aspergillus niger for synthesis of silver nanoparticles. Biobased Mat Bioenerg 2:243-247

Gaikwad SC, Birla SS, Ingle AP, Gade AK, Marcato PD, Rai M, Durán NJ (2013) Screening of different Fusarium species to select potential species for the synthesis of silver nanoparticles. J Braz Chem Soc 24:1974-1982

Gopinath V, Priyadarshini S, Priyadharsshini NM, Pandian K, Velusamy P (2013) Biogenic synthesis of antibacterial silver chloride nanoparticles using leaf extracts of Cissus quadrangulares Linn. Mat Lett 91:224-227

Ingale AG, Chaudhari AN (2013) Biogenic synthesis of nanoparticles and potential applications: an eco-friendly approach. J Nanomed Nanotechol 4:165, doi:10.4172/2157-7439.1000165

Jain N, Bhargava A, Majumdar S, Tarafdar JC, Panwar J (2011) Extracellular biosynthesis and characterization of silver nanoparticles using Aspergillus flavus NJP08: A mechanism perspective. Nanoscale 3:635-641

Kalishwaralal K, Gopalram S, Vaidyanathan R, Deepak V, Pandian SRK, Gurunathan $S$ (2010) Optimization of a-amylase production for the green synthesis of gold nanoparticles. Colloid Surf B Interf 77:174-180

Kashyap PL, Kumar S, Kumar Srivastava AK, Sharma AK (2013) Myconanotechnology in agriculture: a perspective. World J Microbiol Biotechnol 29:191-207

Kumar U, Ranjan AK, Sharan C, Hardikarc AA, Pundle A, Poddar P (2012) Green approach towards size controlled synthesis of biocompatible antibacterial metal nanoparticles in aqueous phase using lysozyme. Curr Nanosci 8:130-140

Leonowicz A, Grzywnowicz K (1981) Quantitative estimation of laccase form in some white-rot fungi using syringaldazine as a substrate. Enzyme Microb Technol 3:55-58

Min SH, Yang JK, Kim JY, Kwon YU (2010) Development of white antibacterial pigment based on silver chloride nanoparticles and mesoporous silica and its polymer composite. Microporous Mesoporous Mater 128:19-25

Morozova OV, Shumakovich GP, Gorbacheva MA, Shleev SV, Yaropolov Al (2007) "Blue" laccases. Biochem Mosc 72:1136-1150

Naik B, Desai V, Kowshik M, Prasad MV, Fernando GF, Ghosh NN (2011) Synthesis of $\mathrm{Ag} / \mathrm{AgCl}$-mesoporous silica nanocomposites using a simple aqueous solution-based chemical method and a study of their antibacterial activity on E. coli. Particuology 9:243-247

Nithya R, Ragunathan R (2009) Synthesis of silver nanoparticle using Pleurotus sajor caju and its antimicrobial study. Digest J Nanomat Biostruct 4:623-629

Paulkumar K, Rajeshkumar S, Gnanajobitha G, Vanaja M, Malarkodi C, Annadurai G (2013) Biosynthesis of Silver Chloride Nanoparticles Using Bacillus subtilis MTCC 3053 and Assessment of Its Antifungal Activity. ISRN Nanomaterials 2013(ID 317963):8, http://dx.doi.org/10.1155/2013/317963

Piontek CK, Antorini M, Choinowski GJ (2002) Crystal structure of a laccase from the fungus Trametes versicolor at 1.90- $\AA$ resolution containing a full complement of coppers. Biol Chem 277:37663-37669

Rangnekar A, Sarma TK, Singh AK, Deka J, Ramesh A, Chattopadhyay A (1997) Retention of enzymatic activity of a-amylase in the reductive synthesis of gold nanoparticles. Langmuir 23:5700-5706

Rubilar O, Diezand MC, Gianfreda L (2008) Transformation of chlorinated phenolic compounds by white rot fungi. Crit Rev Environ Sci Tech 38:227-268

Sanghi R, Verma P (2009) Biomimetic synthesis and characterisation of protein capped silver nanoparticles. Bioresour Technol 100:501-504

Sanghi R, Verma P, Puri S (2001) Enzymatic formation of gold nanoparticles using Phanerochaete chrysosporium. Advan Chem Eng Sci 1:154-162

Sharma S, Mandani S, Sarma TK (2013) Biogenic growth of alloys and core-shell nanostructures using urease as a nanoreactor at ambient condition. Sci Rep 3(2601):1-8

Tortella GR, Rubilar O, Gianfreda L, Valenzuela E, Diez MC (2008) Enzymatic characterization of Chilean native wood-rotting fungi for potential use in the bioremediation of polluted environments with chlorophenols. World J Microbiol Biotechnol 12:2805-2818

Tran QH, Nguyen VQ, Le AT (2013) Silver nanoparticles: synthesis, properties, toxicology, applications and perspectives. Adv Nat Sci: Nanosci Nanotechnol 4:033001
Vigneshwaran N, Kathe A, Varadarajan PV, Nachane R, Balasubramanya RH (2009) Biomimetics of silver nanoparticles by white rot fungus, Phaenerochaete chrysosporium. Colloids Surf B: Biointerf 53:55-59

Wang P, Huang B, Qin X, Zhang X, Dai Y, Wei J, Whangbo MH (2008) Ag@AgCl: A highly efficient and stable photocatalyst active under visible light. Chem Int Ed 47:7931-7933

doi:10.1186/2193-1801-3-645

Cite this article as: Durán et al:: Biogenic silver nanoparticles associated with silver chloride nanoparticles $(\mathrm{Ag} @ \mathrm{AgCl})$ produced by laccase from Trametes versicolor. SpringerPlus 2014 3:645

\section{Submit your manuscript to a SpringerOpen ${ }^{\odot}$ journal and benefit from:}

- Convenient online submission

- Rigorous peer review

- Immediate publication on acceptance

- Open access: articles freely available online

- High visibility within the field

- Retaining the copyright to your article

Submit your next manuscript at $>$ springeropen.com 